\title{
Chapter 4 \\ Physiochemical Characterization and Domain Annotation of ORF1ab \\ Polyprotein of Novel Corona Virus 19
}

The detailed structural analysis of the ORF1ab polyprotein was carried out to study its Physiochemical characterization as well as its domain annotations. Various in silico tools have been used for the said purpose.

\subsection{Physiochemical Characterization of ORF1ab Polyprotein Using Protparam}

Protparam is a tool from Expasy proteomic server, for the annotation of complete physiological and chemical characteristics of the protein. The analysis is completely based on the input sequence and depends on the amino acid characteristics. A detailed annotation of the protein can be performed by the tool (Fig. 4.1).

Inference: The ORF1ab polyprotein is comprised of 7096 amino acids. The Molecular weight and the Isoelectric point are 794,057.79 and 6.32 respectively. This indicates that at the $\mathrm{pH} 6.32$ the protein exists in its zwitter ionic state. Total number of negatively charged residues is the sum of Aspartic acid residues and Glutamic acid residues which is calculated to be 729 amino acids. Similarly the total number of positively charged residues is the total of Arginine and Lysine residues which is calculated to be 678 . The presence of more number of acidic amino acids makes the protein acidic in nature. The instability index of the protein is 33.31 which imparts stability to the protein. The protein is hydrophilic i.e. water soluble which is indicated by its hydropathicity index being -0.070 . 


\begin{tabular}{|c|c|c|c|}
\hline \multicolumn{4}{|c|}{ Number of amino acids: 7096} \\
\hline \multicolumn{4}{|c|}{ Molecular weight: 794057.79} \\
\hline \multicolumn{4}{|c|}{ Theoretical pI: 6.32} \\
\hline \multicolumn{3}{|c|}{ Amino acid composition: } & CSV format \\
\hline Ala (A & 487 & $6.9 \%$ & \\
\hline Arg ( $R$ & 244 & $3.4 \%$ & \\
\hline Asn $(\mathrm{N}$ & 384 & $5.4 \%$ & \\
\hline Asp (D & 389 & $5.5 \%$ & \\
\hline Cys (C & 226 & $3.2 \%$ & \\
\hline Gln $(Q$ & 239 & $3.4 \%$ & \\
\hline Glu ( & 340 & $4.8 \%$ & \\
\hline Gly (G & 412 & $5.8 \%$ & \\
\hline $\mathrm{His}(\mathrm{H}$ & 145 & $2.0 \%$ & \\
\hline Ile (I & 343 & $4.8 \%$ & \\
\hline Leu ( $L$ & 668 & $9.4 \%$ & \\
\hline Lys ( $\mathrm{K}$ & 434 & $6.1 \%$ & \\
\hline Met (M & 168 & $2.4 \%$ & \\
\hline Phe ( $F$ & 349 & $4.9 \%$ & \\
\hline Pro (P & 274 & $3.9 \%$ & \\
\hline Ser $(S$ & 456 & $6.4 \%$ & \\
\hline Thr ( $T$ & 527 & $7.4 \%$ & \\
\hline $\operatorname{Trp}(W$ & 78 & $1.1 \%$ & \\
\hline Tyr (Y & 335 & $4.7 \%$ & \\
\hline Val (V & 598 & $8.4 \%$ & \\
\hline Pyl (0 & 0 & $0.0 \%$ & \\
\hline $\sec (U$ & 0 & $0.0 \%$ & \\
\hline
\end{tabular}
(B) 0
$0.0 \%$
(Z) 0
$0.0 \%$
(X) 0
$0.0 \%$

Total number of negatively charged residues (Asp + Glu): 729

Total number of positively charged residues (Arg + Lys): 678

Fig. 4.1 Partial output of Protparam tool

\subsection{Identification of Domains within the ORF1ab Polyprotein using SMART}




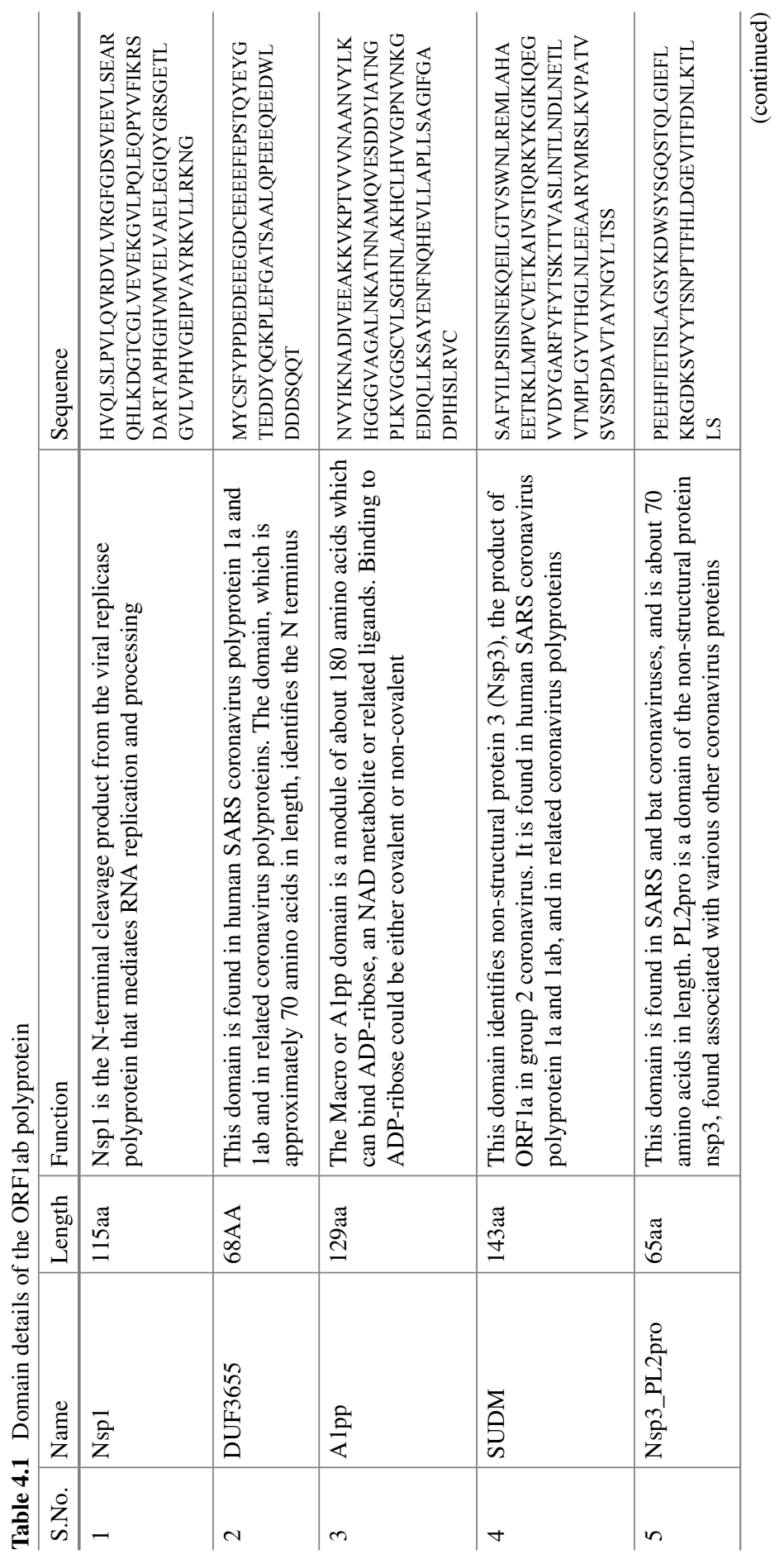




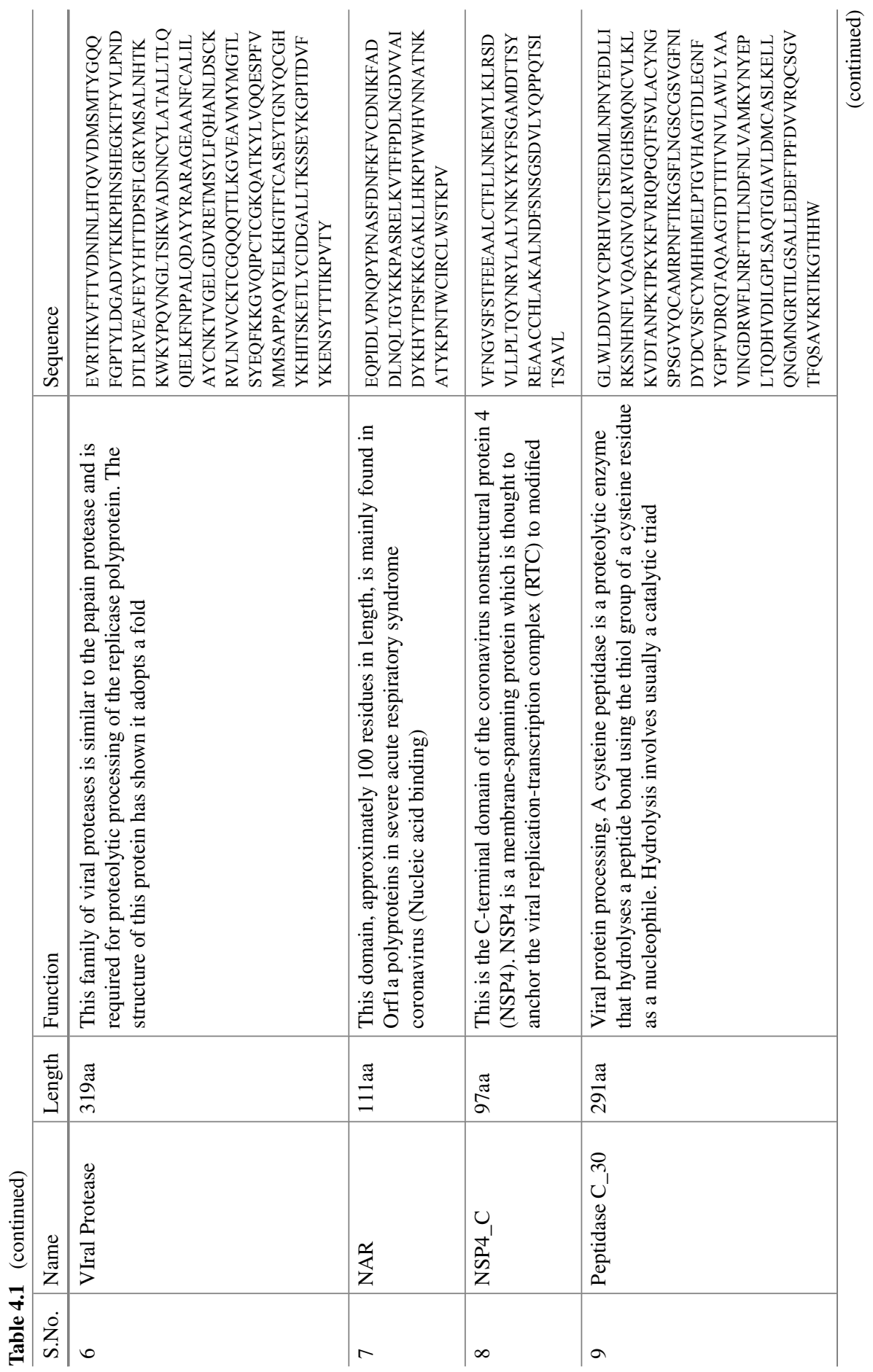




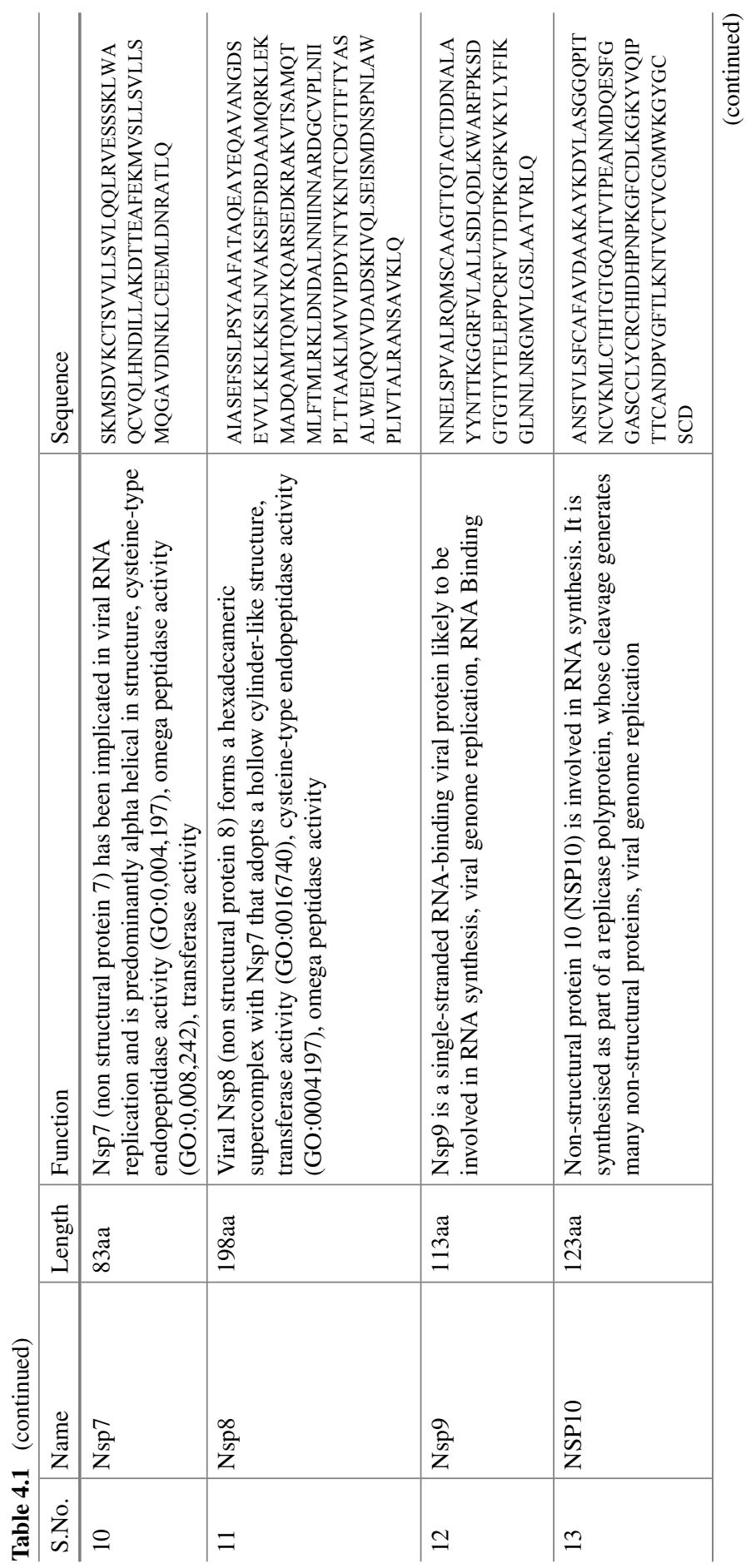




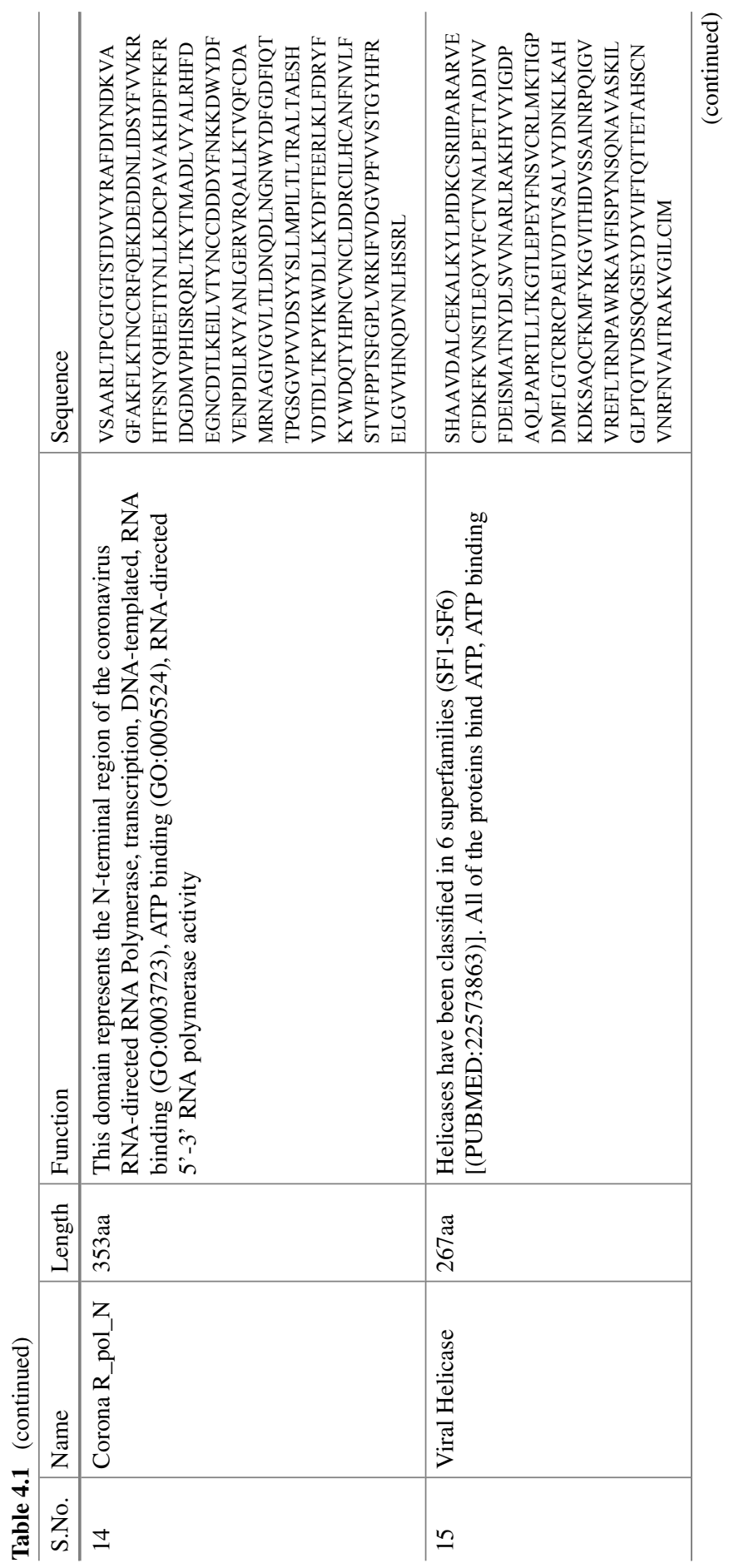




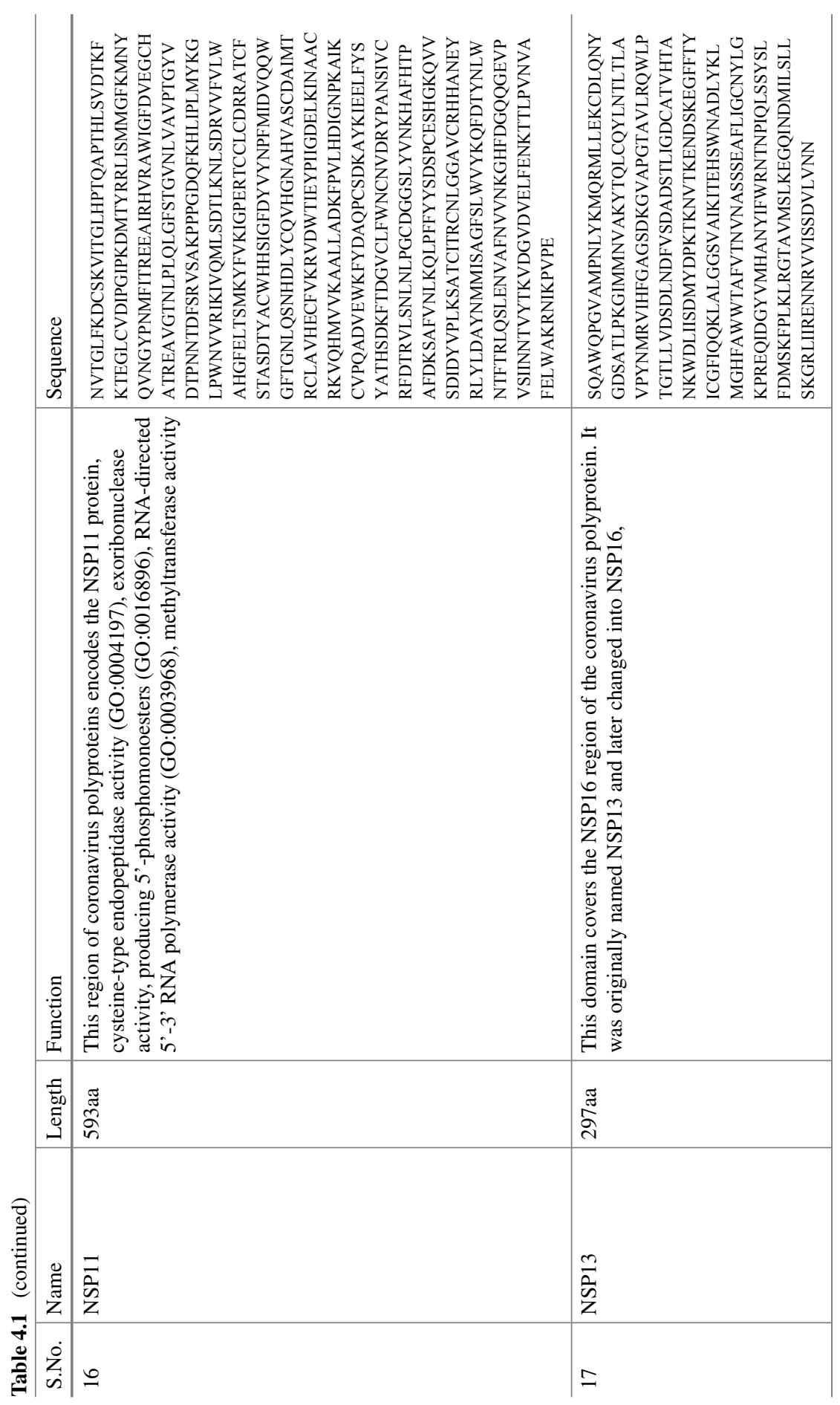




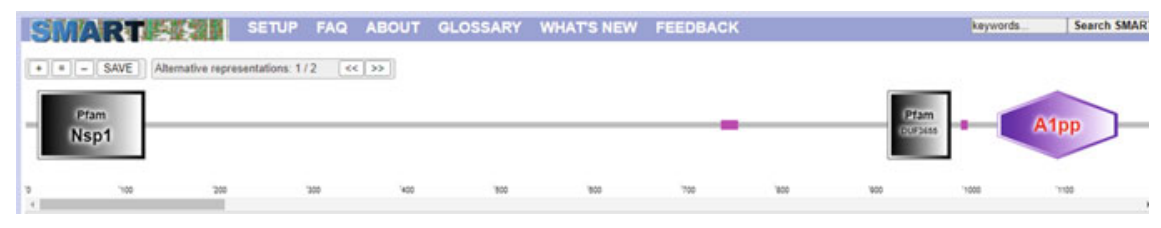

Fig. 4.2 Partial output of SMART

Inference: The above domain analysis as performed by SMART [1] shows that the Query sequence of ORF1ab polyprotein has a total of 17 important domains. The domains include the NSP domains which are involved in the nonstructural protein coding. The other domains include A1 Polyprotein, Viral protease, nucleic acid binding domain, Peptidase, RNA Directed RNA polymerase domain and Viral helicase domain (Fig. 4.2, Table 4.1).

\subsection{The region 4406-5900 of ORF1ab polyprotein of NCoV}

Further the genetic comparison of Novel Corona Virus 19 and MERS Corona Virus showed the region $\mathbf{4 4 0 6}-\mathbf{5 9 0 0}$ of $\mathrm{NCoV}$ to be almost identical in both the groups. This region comprises of domains of evolutionary significance like Corona $\mathrm{R}$ pol $\mathrm{N}(4406-4758)$ and Viral Helicase 1(5325-5925). Thus the further study focuses on analysis of this region.

4406-VSAARLTPCGTGTSTDVVYRAFDIYNDKVAGFAKFLKTNCCRFQEKD

EDDNLIDSYFVVKRHTFSNYQHEETIYNLLKDCPAVAKHDFFKFRIDGDMVPHISRQR LTKYTMADLVYALRHFDEGNCDTLKEILVTYNCCDDDYFNKKDWYDFVENPDILRVYA NLGERVRQALLKTVQFCDAMRNAGIVGVLTLDNQDLNGNWYDFGDFIQTTPGSGVPVV DSYYSLLMPILTLTRALTAESHVDTDLTKPYIKWDLLKYDFTEERLKLFDRYFKYWDQ TYHPNCVNCLDDRCILHCANFNVLFSTVFPPTSFGPLVRKIFVDGVPFVVSTGYHFRE LGVVHNQDVNLHSSRLSFKELLVYAADPAMHAASGNLLLDKRTTCFSVAALTNNVAFQ TVKPGNFNKDFYDFAVSKGFFKEGSSVELKHFFFAQDGNAAISDYDYYRYNLPTMCDI RQLLFVVEVVDKYFDCYDGGCINANQVIVNNLDKSAGFPFNKWGKARLYYDSMSYEDQ DALFAYTKRNVIPTITQMNLKYAISAKNRARTVAGVSICSTMTNRQFHQKLLKSIAAT RGATVVIGTSKFYGGWHNMLKTVYSDVENPHLMGWDYPKCDRAMPNMLRIMASLVLAR KHTTCCSLSHRFYRLANECAQVLSEMVMCGGSLYVKPGGTSSGDATTAYANSVFNICQ AVTANVNALLSTDGNKIADKYVRNLQHRLYECLYRNRDVDTDFVNEFYAYLRKHFSMM ILSDDAVVCFNSTYASQGLVASIKNFKSVLYYQNNVFMSEAKCWTETDLTKGPHEFCS QHTMLVKQGDDYVYLPYPDPSRILGAGCFVDDIVKTDGTLMIERFVSLAIDAYPLTKH PNQEYADVFHLYLQYIRKLHDELTGHMLDMYSVMLTNDNTSRYWEPEFYEAMYTPHTV LQAVGACVLCNSQTSLRCGACIRRPFLCCKCCYDHVISTSHKLVLSVNPYVCNAPGCD VTDVTQLYLGGMSYYCKSHKPPISFPLCANGQVFGLYKNTCVGSDNVTDFNAIATCDW TNAGDYILANTCTERLKLFAAETLKATEETFKLSYGIATVREVLSDRELHLSWEVGKP RPPLNRNYVFTGYRVTKNSKVQIGEYTFEKGDYGDAVVYRGTTTYKLNVGDYFVLTSH TVMPLSAPTLVPQEHYVRITGLYPTLNISDEFSSNVANYQKVGMQKYSTLQGPPGTGK SHFAIGLALYYPSARIVYTACSHAAVDALCEKALKYLPIDKCSRIIPARARVECFDKF KVNSTLEQYVFCTVNALPETTADIVVFDEISMATNYDLSVVNARLRAKHYVYIGDPAQ LPAPRTLLTKGTLEPEYFNSVCRLMKTIGPDMFLGTCRRCPAEIVDTVSALVYDNKLK AHKDKSAQCFKMFYKGVITHDVSSAINRPQIGVVREFLTRNPAWRKAVFISPYNSQNA VASKILGLPTQTVDSSQGSEYDYVIFTQTTETAHSCNVNRFNVAITRAKVGILCIM-5900 
Length of the sequence: 1495 amino acids.

Molecular weight is: $169,186.16$.

Isoelectric point: 7.31 .

\subsection{The Secondary Structural Conformations of the Region 4406-5900}

SOPMA is an online executable tool for the structural annotation of proteins [2]. The tool predicts the detailed secondary structural confirmation of protein with respect to each amino acid in it. Based on the SOPMA annotations the composition percentage of each kind of secondary structures like helix, coil, extended strand etc. can be calculated (Fig. 4.3).

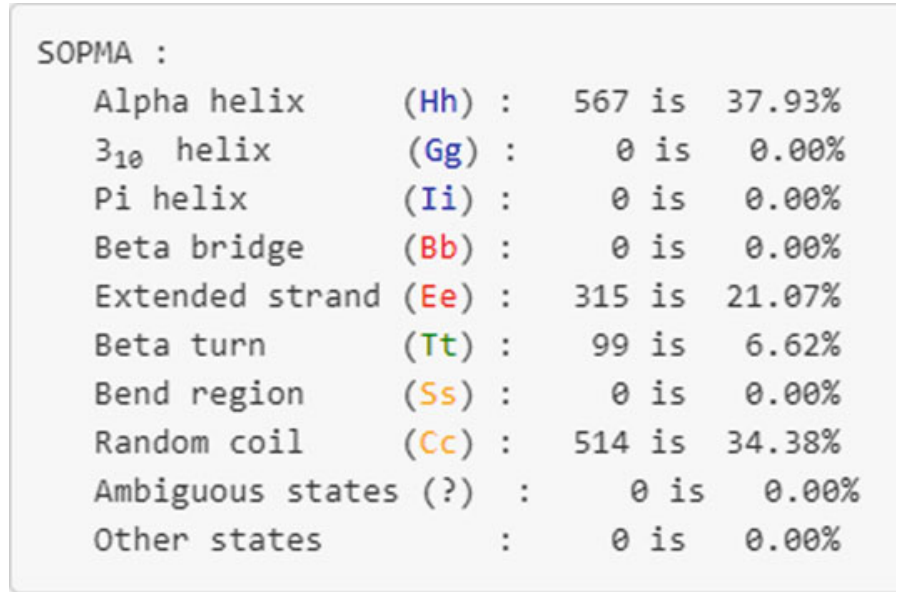

Fig. 4.3 Partial output of SOPMA tool

As evident, residues forming helix are more than those of sheets, confirming the hydrophilic nature of the peptide.

\subsection{D Structure prediction using Phyre}

The phyre [3] result indicates that the selected sequence (region 4406-5900 of ORF1ab polyprotein of $\mathrm{NCoV}$ ) can be structurally represented by the pdb id $7 \mathrm{btfA}$. The subject sequence being represented by $7 \mathrm{btfA}$ shares $100 \%$ identity to the submitted query sequence with the confidence sore of $100 \%$. The pdb id codes for the structure of SARS Corona Virus 2 RNA-dependent RNA polymerase. This structure can be used for further analysis (Fig. 4.4). 


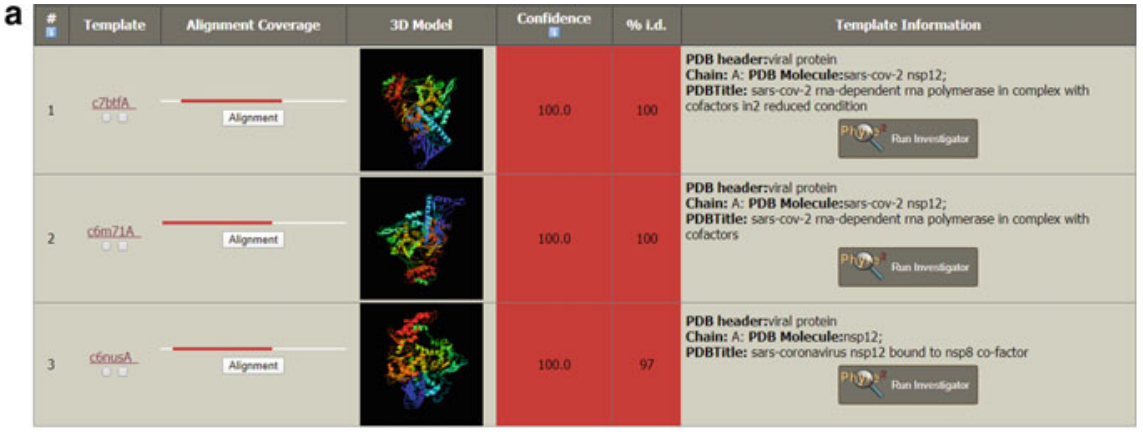

b Top model

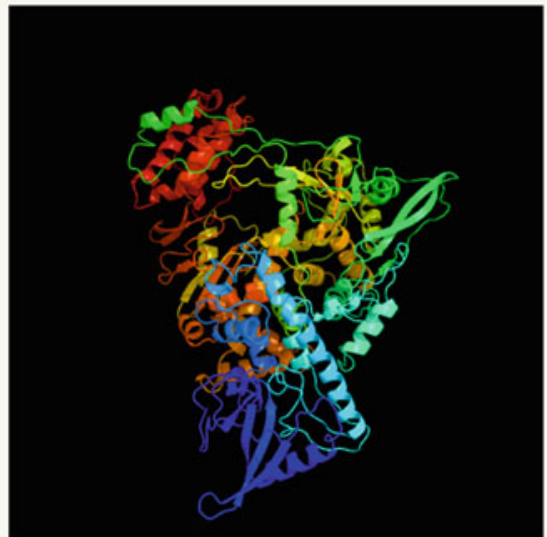

Image coloured by rainbow $\mathrm{N} \rightarrow \mathrm{C}$ terminus Model dimensions $(\AA)$ : X:73.000 Y:84.083 Z:113.658
Model (left) based on template c $\underline{\text { 7btfA }}$

PDB header:viral protein

Chain: A: PDB Molecule:sars-cov-2 nsp12;

PDBTitle: sars-cov-2 ma-dependent ma polymerase

in complex with cofactors in2 reduced condition

Confidence and coverage

Confidence: $\quad 100.0 \%$ Coverage: $61 \%$

914 residues ( $61 \%$ of your sequence) have been modelled with $100.0 \%$ confidence by the single highest scoring template.

Additional confident templates have been detected (see Domain analysis) which cover other regions of your sequence.

1490 residues $(100 \%)$ could be modelled at $>90 \%$ confidence using multiple-templates.

You may wish to try resubmitting your sequence in "intensive" mode to model more of your sequence.

\section{$3 \mathrm{D}$ viewing}

Interactive 3D view in JSmol

For other options to view your downloaded structure offline see the FAQ
C

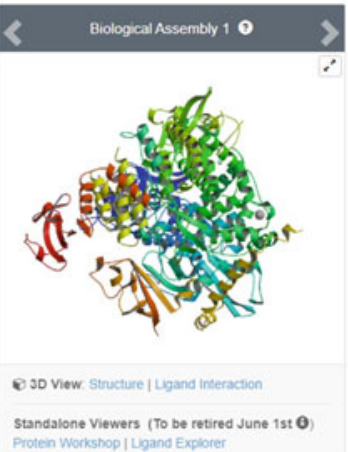

\section{BTF}

Dolsplay Fies -

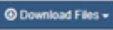

SARS-CoV-2 RNA-dependent RNA polymerase in complex with cofactors in reduced condition

DOI: 10.22101po078TF/pdo EMDataResource: EMO-30178

Classification: VIRAL PROTEIN

Organism(s): Severe acute respirationy syndrome corconavius 2

Expression System: Eschenichia coll BL21(DE3)

Deposited: 2020-04-01 Released: $2020-04-08$

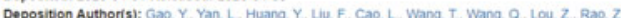

Funding Organization(s): Chinese Academy of Sciences. National Naturas Science Foundation of China (NSFC) Ministry of Science and Technology (Most, China)

Experimental Data Snapshot

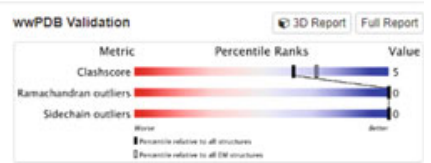

Fig. 4.4 a, $b$ and $\mathbf{c}$ Partial output of Phyre and PDB 


\title{
4.6 3D Structure Visualization of the SARS Corona Virus 2 RNA-Dependent RNA Polymerase Protein in RASMOL
}

The structure 7BTF corresponding to the Structure of SARS Corona Virus 2 RNADependent RNA Polymerase was downloaded from PDB and visualized in Rasmol [4]. The subject sequence shows the structure as shown below (Fig. 4.5).

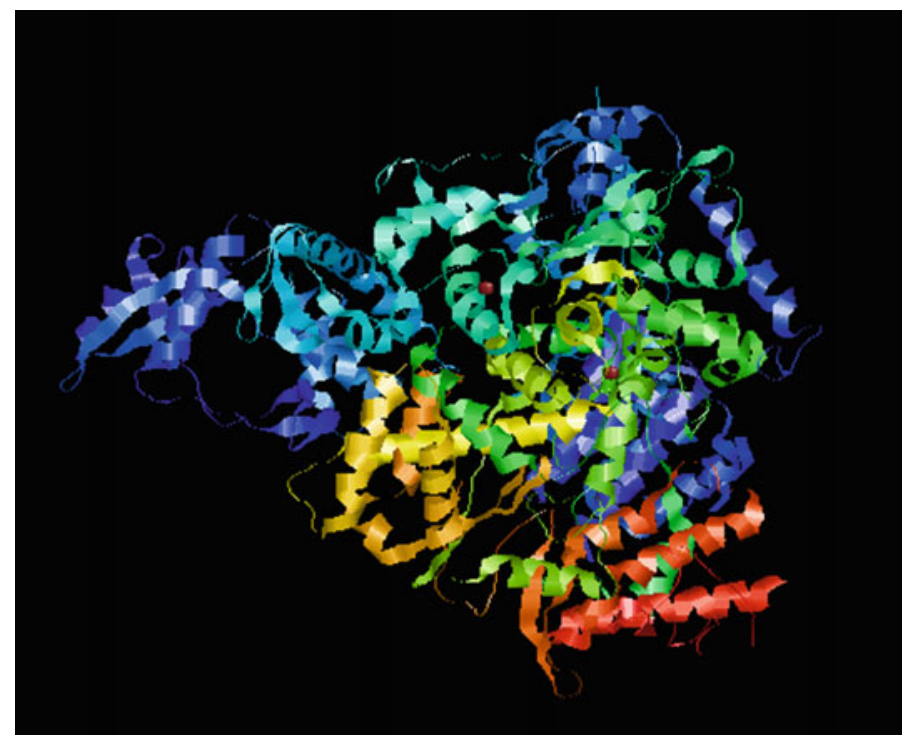

Fig. 4.5 Rasmol visualization of RNA-dependent RNA polymerase protein

SADAQSFLNRVCGVSAARLTPCGTGTSTDVVYRAFDIYNDKVAGFAKFLKTNCCRFQEKDEDDNLIDSYFVVKRH TFSNYQHEETIYNLLKDCPAVAKHDFFKFRIDGDMVPHISRQRLTKYTMADLVYALRHFDEGNCDTLKEILVTYNC CDDDYFNKKDWYDFVENPDILRVYANLGERVRQALLKTVQFCDAMRNAGIVGVLTLDNQDLNGNWYDFGDFIQ TTPGSGVPVVDSYYSLLMPILTLTRALTAESHVDTDLTKPYIKWDLLKYDFTEERLKLFDRYFKYWDQTYHPNCV NCLDDRCILHCANFNVLFSTVFPPTSFGPLVRKIFVDGVPFVVSTGYHFRELGVVHNQDVNLHSSRLSFKELLVYAA

\begin{abstract}
DPAMHAASGNLLLDKRTTCFSVAALTNNVAFQTVKPGNFNKDFYDFAVSKGFFKEGSSVELKHFFFAQDGNAAIS DYDYYRYNLPTMCDIRQLLFVVEVVDKYFDCYDGGCINANQVIVNNLDKSAGFPFNKWGKARLYYDSMSYEDQ DALFAYTKRNVIPTITQMNLKYAISAKNRARTVAGVSICSTMTNRQFHQKLLKSIAATRGATVVIGTSKFYGGWHN MLKTVYSDVENPHLMGWDYPKCDRAMPNMLRIMASLVLARKHTTCCSLSHRFYRLANECAQVLSEMVMCGGSL YVKPGGTSSGDATTAYANSVFNICQAVTANVNALLSTDGNKIADKYVRNLQHRLYECLYRNRDVDTDFVNEFYA YLRKHFSMMILSDDAVVCFNSTYASQGLVASIKNFKSVLYYQNNVFMSEAKCWTETDLTKGPHEFCSQHTMLVK QGDDYVYLPYPDPSRILGAGCFVDDIVKTDGTLMIERFVSLAIDAYPLTKHPNQEYADVFHLYLQYIRKLHDELTG HMLDMYSVMLTNDNTSRYWEPEFYEAMYTPHTVLQHHHHHHHHHH
\end{abstract}

The region that is matching between the two sequences is $14-910$ of the selected gene region on the pdb structure (Fig. 4.6). 


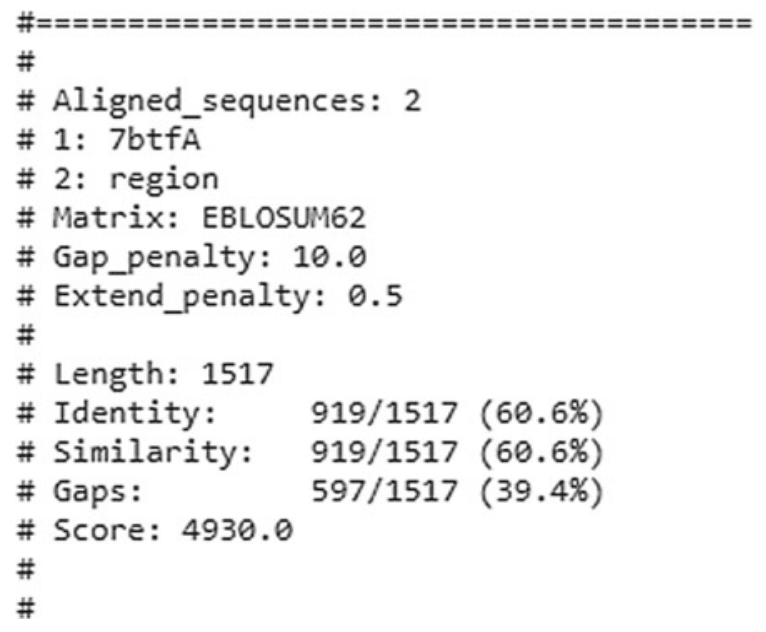

Fig. 4.6 Alignment of the subject sequence with the selected protein region of 4406-5900 of query polyprotein

\subsection{Prediction of Disordered Sites Within the Protein Structure Based on GLOBPLOT}

Inference: The above result of Globplot [5] indicates that the regions that are more prone for mutation or the regions of disorder are 2-7, 20-29, 213-236, 321-329, $413-420,503507,614-624,673-688,828-841$. The longest region within these is 213-236 (Fig. 4.7).

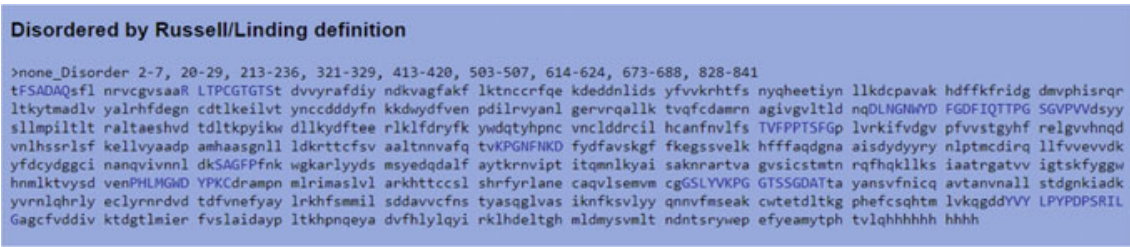

Fig. 4.7 Partial output of Globplot 


\section{References}

1. Schultz Jörg et al (2000) SMART: a web-based tool for the study of genetically mobile domains. Nucleic Acids Res 28(1):231-234 PMID: 10592234

2. Geourjon C, Deléage G (1995) SOPMA: significant improvements in protein secondary structure prediction by consensus prediction from multiple alignments. Bioinformatics 11(6):681-684

3. Kelley L, Mezulis S, Yates C et al (2015) The Phyre 2 web portal for protein modeling, prediction and analysis. Nat Protoc 10:845-858. https://doi.org/10.1038/nprot.2015.053

4. Sayle R, James Milner-White E (1995) The currently preferred literature reference to RasMol is: "RasMol: Biomolecular graphics for all". Trends in Biochem Sci (TIBS) 20(9):374

5. Linding R, Russell RB, Neduva V, Gibson TJ (2003) GlobPlot: exploring protein sequences for globularity and disorder. Nucleic Acids Res 31(13):3701-3708. https://doi.org/10.1093/nar/ gkg519 